SUBJECT AREAS:

SOLAR CELLS

ELECTRONIC DEVICES

Received

12 August 2014

Accepted

4 November 2014

Published

21 November 2014

Correspondence and requests for materials should be addressed to K.N. (nakayama@yz. yamagata-u.ac.jp) or H.Y. (hyamada@ms. naist.jp)

* These authors contributed equally to this work.

\section{Photoprecursor approach as an effective means for preparing multilayer organic semiconducting thin films by solution} processes

\author{
Yuji Yamaguchi ${ }^{*}$, Mitsuharu Suzuki ${ }^{2 *}$, Takao Motoyama', Shuhei Sugii ${ }^{2}$, Chiho Katagiri', \\ Katsuya Takahira ${ }^{3}$, Shinya Ikeda ${ }^{2}$, Hiroko Yamada ${ }^{2,4} \&$ Ken-ichi Nakayama ${ }^{1,4}$
}

\begin{abstract}
'Department of Organic Device Engineering, Yamagata University, 4-3-16 Jonan, Yonezawa, Yamagata 992-8510, Japan, ${ }^{2}$ Graduate School of Materials Science, Nara Institute of Science and Technology, 89 16-5 Takayama-cho, Ikoma, Nara 630-0192, Japan, ${ }^{3}$ Department of Polymer Science and Engineering, Yamagata University, 4-3-16 Jonan, Yonezawa, Yamagata 992-8510, Japan, ${ }^{4}$ CREST, JST, 4-1-8 Honcho, Kawaguchi, Saitama 332-0012, Japan.
\end{abstract}

The vertical composition profile of active layer has a major effect on the performance of organic photovoltaic devices (OPVs). While stepwise deposition of different materials is a conceptually straightforward method for controlled preparation of multi-component active layers, it is practically challenging for solution processes because of dissolution of the lower layer. Herein, we overcome this difficulty by employing the photoprecursor approach, in which a soluble photoprecursor is solution-deposited then photoconverted in situ to a poorly soluble organic semiconductor. This approach enables solution-processing of the p-i-n triple-layer architecture that has been suggested to be effective in obtaining efficient OPVs. We show that, when 2,6-dithienylanthracene and a fullerene derivative $\mathrm{PC}_{71} \mathrm{BM}$ are used as donor and acceptor, respectively, the best $\mathbf{p}-\mathbf{i}-\mathrm{n}$ OPV affords a higher photovoltaic efficiency than the corresponding $p-n$ device by $24 \%$ and bulk-heterojunction device by $67 \%$. The photoprecursor approach is also applied to preparation of three-component p-i-n films containing another donor 2,6-bis(5' -(2-ethylhexyl)-(2,2'-bithiophen)-5$\mathrm{yl}$ )anthracene in the i-layer to provide a nearly doubled efficiency as compared to the original two-component $p$-i-n system. These results indicate that the present approach can serve as an effective means for controlled preparation of well-performing multi-component active layers in OPVs and related organic electronic devices.

 he active layer of organic photovoltaic devices (OPVs) is composed of p-type and n-type semiconductors, and its vertical composition profile significantly affects the efficiency of charge-carrier generation and transportation, thus has substantial impact on the photovoltaic performance ${ }^{1-3}$. Accordingly, controlled preparation of active layers is one of the central issues in the development of OPVs. A conceptually simple approach for achieving a desirable vertical composition profile is sequential, layer-by-layer deposition of different materials, which can be done relatively straightforwardly via vacuum evaporation. On the other hand, this approach is a considerable challenge for solution processes owing to dissolution of the lower layer during deposition of the upper layer. In order to overcome this problem, several strategies have been proposed including the use of orthogonal solubility ${ }^{4-11}$ and post-deposition fixation ${ }^{12,13}$; however, the range of applicable materials and the variety of processing conditions are still limited.

Herein, we present a unique 'photoprecursor approach' as a new option for layer-by-layer preparation of multicomponent organic semiconducting films through solution processes. Our approach employs $\alpha$-diketone-type photoprecursors of acenes that can be converted to corresponding acenes by extrusion of CO molecules upon visible light irradiation ${ }^{14}$. We have previously shown that this type of photoprecursors can be employed in preparation of solution-processed organic field-effect transistors to yield good semiconducting performances comparable to those observed in vacuum-deposited films ${ }^{15,16}$. Additionally, the quality of resulting films can be tuned by photoirradiation conditions such as intensity and duration ${ }^{16}$. By taking advantage of this photoprecursor approach, we have also solution-processed $\mathrm{p}-\mathrm{n}$ double-layer structures containing acene compounds that are hardly soluble ${ }^{17}$. The present work expands the scope of photoprecursor approach to fabrication of the $\mathrm{p}-\mathrm{i}-\mathrm{n}$ 
triple-layer architecture which is more relevant to high-performance OPVs as well as other organic electronic devices such as light-emitting diodes ${ }^{18}$ and photoconductors ${ }^{19}$.

The $\mathrm{p}-\mathrm{i}-\mathrm{n}$ organic photovoltaic film typically has a $\mathrm{p}: \mathrm{n}$ composite layer (inter layer or i-layer) sandwiched between neat $\mathrm{p}$ - and n-type semiconductors ( $\mathrm{p}$ - and n-layers, respectively) ${ }^{20-22}$. It has been suggested that, upon proper choice of materials and structural parameters, the $\mathrm{p}-\mathrm{i}-\mathrm{n}$ architecture can afford high photovoltaic performance derived from the combination of efficient carrier generation in the i-layer and efficient carrier transportation in the p-and $\mathrm{n}$-layers. This structure is also advantageous in that each layer can be designed and optimized separately, allowing the systematic evaluation of different combinations of materials to obtain optimal photovoltaic performances. Among others, Leo et al. extensively investigated the $\mathrm{p}-\mathrm{i}-\mathrm{n}$ system having a co-deposited $\mathrm{i}$-layer and chemically doped $\mathrm{p}$ - and n-layers fabricated via vacuum evaporation to achieve comparatively high conductivity and excellent device performance ${ }^{23,24}$. Matsuo et al. judiciously utilized a thermally convertible precursor of benzoporphyrin, a hardly soluble organic p-type material, to prepare $\mathrm{p}-\mathrm{i}-\mathrm{n}$ active layers by solution deposition ${ }^{25}$. The resulting device showed a considerably higher photovoltaic performance (power conversion efficiency, $\mathrm{PCE}=4.5 \%$ ) compared to the corresponding $\mathrm{p}-\mathrm{n}$-type device $(\mathrm{PCE}=2.3 \%)$. (The general device structure of these $\mathrm{p}-\mathrm{i}-\mathrm{n}$ and $\mathrm{p}-\mathrm{n}$ devices is [ITO/PEDOT : PSS/active layer/BCP/Al]. Note that the PCE was improved to $5.2 \%$ by employing NBphen buffer instead of BCP in the $\mathrm{p}-\mathrm{i}-\mathrm{n}$ system.)

In the following sections, we carefully examine OPVs prepared through the photoprecursor approach. The first part of this report systematically compares solution-processed $\mathrm{p}-\mathrm{i}-\mathrm{n}$ active layers with the corresponding $\mathrm{p}-\mathrm{n}$ and bulk-heterojunction (BHJ) films employing 2,6-dithienylanthracene (DTA ${ }^{26}$ as p-type semiconductor and $[6,6]$-phenyl- $\mathrm{C}_{71}$-butyric acid methyl ester $\left(\mathrm{PC}_{71} \mathrm{BM}\right)$ as $n$-type semiconductor. It was previously demonstrated that the photoreaction to generate hardly soluble DTA from the well-soluble $\alpha$-diketone-type photoprecursor DTADK (Figure 1a) readily proceeded in the solid state, and that the thin film of DTA prepared via the photoprecursor approach showed appreciable semiconducting properties $^{14}$. Among the three different types, the $\mathrm{p}-\mathrm{i}-\mathrm{n}$ architecture affords the best photovoltaic performance associated with favorable electrical properties in the dark. In the second part of this report, we examine 'hetero $\mathrm{p}-\mathrm{i}-\mathrm{n}$ ' devices in which 2,6-bis $\left(5^{\prime}\right.$-(2-ethylhexyl)(2,2'-bithiophen)-5-yl)anthracene (EH-DBTA, Figure 1b) is employed for the i-layer, while DTA is used in the p-layer. (On the other hand, a device is referred to as 'homo $\mathrm{p}-\mathrm{i}-\mathrm{n}$ ' in the following when both the $i$ - and p-layers are based on the same p-type material.) EH-DBTA is designed, as compared with DTA, to better fulfill the desirable properties for the i-layer material (i.e., high photoabsorption capability and miscibility with the n-type material), and this relatively simple structural modification already leads to nearly (a)
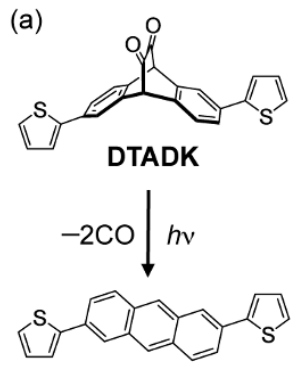

DTA (b)
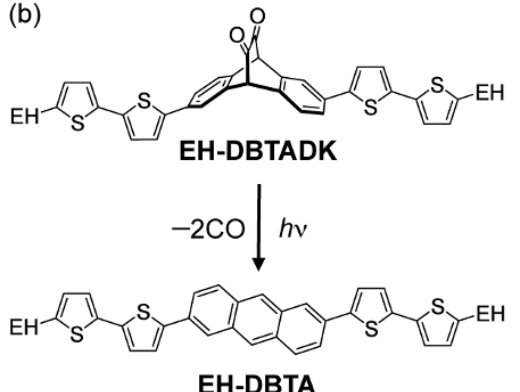

(EH = 2-ethylhexyl)
Figure $1 \mid$ Photo-induced generation of anthracene-based p-type semiconductors from the corresponding $\alpha$-diketone-type precursors; (a) DTA from DTADK, (b) EH-DBTA from EH-DBTADK. twofold enhancement in PCE. These results demonstrate that the photoprecursor approach serves as an effective means for controlled preparation of well-performing multi-component organic active layers.

\section{Results and Discussion}

The deposition process of organic active layers via the photoprecursor approach is illustrated in Figure 2. The p-layer was prepared by spin-coating of DTADK in chloroform $(250 \mu \mathrm{l}, 800 \mathrm{rpm}, 30 \mathrm{~s})$ followed by photoirradiation ( $470 \mathrm{~nm} \mathrm{LED}, 550 \mathrm{~mW} \mathrm{~cm}^{-2}, 30 \mathrm{~min}$ ) to effect the in-situ conversion of DTADK to DTA. The i-layer was deposited in the same manner by using a mixed solution (DTADK: $\mathrm{PC}_{71} \mathrm{BM}$ or EH-DBTADK: $\mathrm{PC}_{71} \mathrm{BM}$ ). The anthracenediketone skeleton can be smoothly converted to anthracene even in the presence of $\mathrm{PC}_{71} \mathrm{BM}^{27}$. The optimal weight ratio between donor and acceptor in the mixed solution was experimentally determined to be 2: 1 (Supplementary Table S1 and Figure S11) which was employed for deposition of i-layers throughout this study. The nlayer was prepared by spin-coating of a chloroform solution of $\mathrm{PC}_{71} \mathrm{BM}(250 \mu \mathrm{l}, 800 \mathrm{rpm}, 30 \mathrm{~s})$. The thicknesses of organic layers were controlled by solution concentration (Table 1).

The photovoltaic performances of the $\mathrm{p}-\mathrm{n}, \mathrm{BHJ}$, and $\mathrm{p}-\mathrm{i}-\mathrm{n}$ devices prepared using different solution concentrations are summarized in Table 1 . We firstly compare three devices A, B, and E in order to elucidate differences originating from the device architecture. Note that the concentrations of deposition solutions are consistent within each layer type (i.e., p-, n-, or i-layer) among these three devices. Their $J-V$ curves in the dark and under AM1.5G illumination are shown in Figure 3. All of the three devices showed open circuit voltages $\left(V_{\mathrm{OC}}\right.$ ) of $\geq 0.8 \mathrm{~V}$, which is reasonable if one considers the relatively large energy difference between the highest occupied molecular orbital (HOMO) of DTA $(-5.5 \mathrm{eV})^{27}$ and the lowest unoccupied molecular orbital (LUMO) of $\mathrm{PC}_{71} \mathrm{BM}(-4.3 \mathrm{eV})^{28,29}$. Here, the Voc in an OPV generally correlates to the energy difference between the LUMO of accepter and the HOMO of donor minus the exciton binding energy ${ }^{30-32}$. High $V o c$ of up to ca. $1 \mathrm{~V}$ have been observed in polymer $/ \mathrm{PC}_{71} \mathrm{BM}$ systems in which the polymers are similar to DTA in terms of the HOMO level ${ }^{33}$. The $\mathrm{p}-\mathrm{n}$ device A yielded a PCE of $1.21 \%$ associated with a short circuit current density $\left(J_{\mathrm{SC}}\right)$ of $2.81 \mathrm{~mA} \mathrm{~cm}^{-2}$, the highest fill factor (FF) of $53.6 \%$, the lowest series resistance $\left(R_{\mathrm{S}}\right)$ of $36 \Omega \mathrm{cm}^{2}$, and the highest shunt resistance $\left(R_{\mathrm{SH}}\right)$ of $2134 \Omega \mathrm{cm}^{2}$. The BHJ device B exhibited a higher $J_{\mathrm{SC}}$ of $2.92 \mathrm{~mA} \mathrm{~cm}^{-2}$, but a significantly lower FF of $29.3 \%$, resulting in a PCE of $0.90 \%$. The homo $\mathrm{p}-\mathrm{i}-\mathrm{n}$ device $\mathrm{E}$ gave a good electrical properties with a higher FF of $46.1 \%$ and a lower $R_{\mathrm{S}}$ of $51 \Omega \mathrm{cm}^{2}$, in spite of the greater overall film thickness $(123 \mathrm{~nm})$ as compared to device B $(67 \mathrm{~nm})$. As a result, device $E$ achieved the highest $J_{\mathrm{SC}}$ of $3.64 \mathrm{~mA} \mathrm{~cm}^{-2}$ and PCE of $1.38 \%$ among the three devices.

The external quantum efficiency (EQE) and estimated internal quantum efficiency (IQE) of the three devices are plotted with $\mathrm{UV}$-vis absorption spectra of the organic films in Figure 4. Since the absorption of DTA extends only up to ca. $450 \mathrm{~nm}^{26}, \mathrm{PC}_{71} \mathrm{BM}$ is mostly responsible for the photocurrent sensitivity in the longer wavelength region (450-700 $\mathrm{nm}$ ). The $\mathrm{p}-\mathrm{n}$ device A showed higher absorbance than the $\mathrm{BHJ}$ device $\mathrm{B}$; however, it gave significantly lower EQE of only $20 \%$ at maximum (Figure $4 \mathrm{a}$ ) and thus lower IQE. This low IQE in device $\mathrm{A}$ is assumed to originate from the planar-junction structure, which is disadvantageous for charge photogeneration because of the limited donor-acceptor (D-A) interface area and the short exciton diffusion length in organic films (ca. $3.1 \mathrm{~nm}$ in $\left.\mathrm{PC}_{71} \mathrm{BM}\right)^{34}$. Device $\mathrm{B}$ showed weaker absorption peaks (Figure $4 \mathrm{~b}$ ) because of the lower $\mathrm{PC}_{71} \mathrm{BM}$ content, while its activelayer thickness is similar to that of the $\mathrm{p}-\mathrm{n}$ device $\mathrm{A}$ (75 and $67 \mathrm{~nm}$ for devices $\mathrm{A}$ and $\mathrm{B}$, respectively). Nevertheless, the $\mathrm{BHJ}$ device showed higher sensitivity than the $\mathrm{p}-\mathrm{n}$ device, associated with much higher IQE of $50 \%$ at the absorption maximum of DTA around 


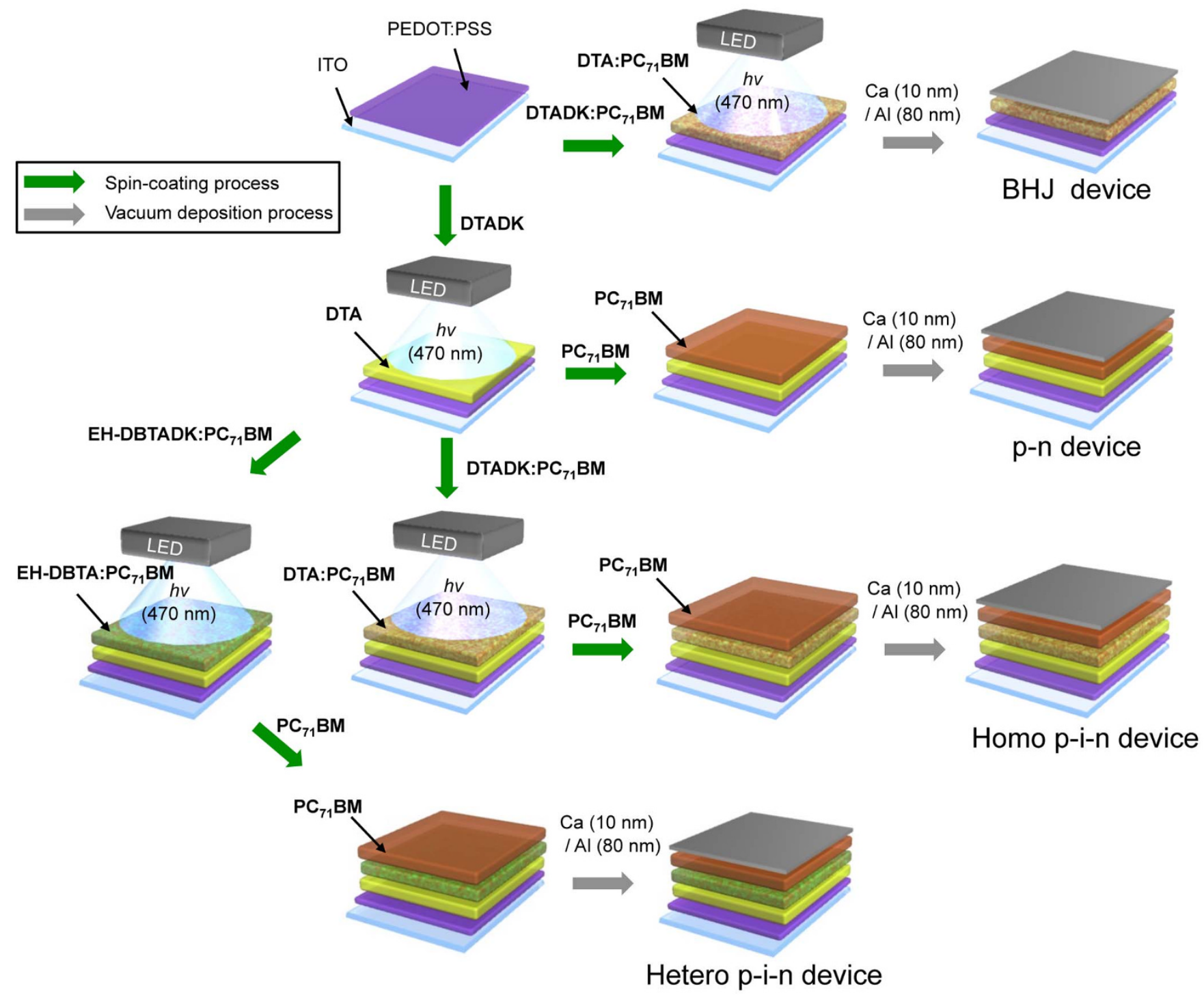

Figure 2 Schematic description of fabrication procedure of the four different types of OPVs studied in this work (BHJ, p-n, homo p-i-n, and hetero p-i-n devices). DTA and EH-DBTA are deposited through the photoprecursor approach using DTADK and EH-DBTADK as photoprecursor, respectively. Note that the homo $\mathrm{p}-\mathrm{i}-\mathrm{n}$ device contains the same $\mathrm{p}$-type material in the $\mathrm{p}$ - and i-layers, while the hetero $\mathrm{p}-\mathrm{i}-\mathrm{n}$ device has different $\mathrm{p}$-type materials between those two layers.

Table $1 \mid$ Active-layer thicknesses and photovoltaic parameters of the best performing devices prepared through the photoprecursor approach. [a,b]

\begin{tabular}{|c|c|c|c|c|c|c|c|c|c|}
\hline Device & Structure & $\begin{array}{l}\text { Solution concentration } \\
\qquad\left(\mathrm{mg} \mathrm{m}^{-1}\right)^{[\mathrm{cc}]}\end{array}$ & $\begin{array}{l}\text { Active-layer } \\
\text { thickness (nm) }\end{array}$ & $J_{\mathrm{SC}}\left(\mathrm{mA} \mathrm{cm}{ }^{-2}\right)$ & $V_{\text {oc }}(\mathrm{V})$ & $\mathrm{FF}(\%)$ & PCE (\%) & $R_{\mathrm{S}}\left(\Omega \mathrm{cm}^{2}\right)$ & $R_{\mathrm{SH}}\left(\Omega \mathrm{cm}^{2}\right)$ \\
\hline $\bar{A}$ & $p-n$ & $5 / 10$ & 75 & 2.81 & 0.80 & 53.6 & 1.21 & 36 & 2134 \\
\hline $\begin{array}{l}E \\
F \\
G\end{array}$ & Homo p-i-n & $\begin{array}{l}5 / 10 / 10 \\
5 / 20 / 10 \\
5 / 30 / 10\end{array}$ & $\begin{array}{l}123 \\
153 \\
223\end{array}$ & $\begin{array}{l}3.64 \\
3.78 \\
3.99\end{array}$ & $\begin{array}{l}0.82 \\
0.89 \\
0.88\end{array}$ & $\begin{array}{l}46.1 \\
44.7 \\
38.4\end{array}$ & $\begin{array}{l}1.38 \\
1.50 \\
1.34\end{array}$ & $\begin{array}{l}51 \\
59 \\
85\end{array}$ & $\begin{array}{r}1247 \\
1174 \\
721\end{array}$ \\
\hline $\begin{array}{l}\mathrm{H} \\
\mathrm{I} \\
\mathrm{J}\end{array}$ & Hetero $\mathrm{p}-\mathrm{i}-\mathrm{n}$ & $\begin{array}{l}5 / 5 / 5 \\
5 / 10 / 5 \\
5 / 20 / 5\end{array}$ & $\begin{array}{r}71 \\
110 \\
164\end{array}$ & $\begin{array}{l}4.82 \\
5.78 \\
5.32\end{array}$ & $\begin{array}{l}0.86 \\
0.91 \\
0.93\end{array}$ & $\begin{array}{l}52.6 \\
55.0 \\
51.0\end{array}$ & $\begin{array}{l}2.17 \\
2.89 \\
2.53\end{array}$ & $\begin{array}{l}24 \\
19 \\
26\end{array}$ & $\begin{array}{l}1193 \\
1327 \\
1164\end{array}$ \\
\hline
\end{tabular}




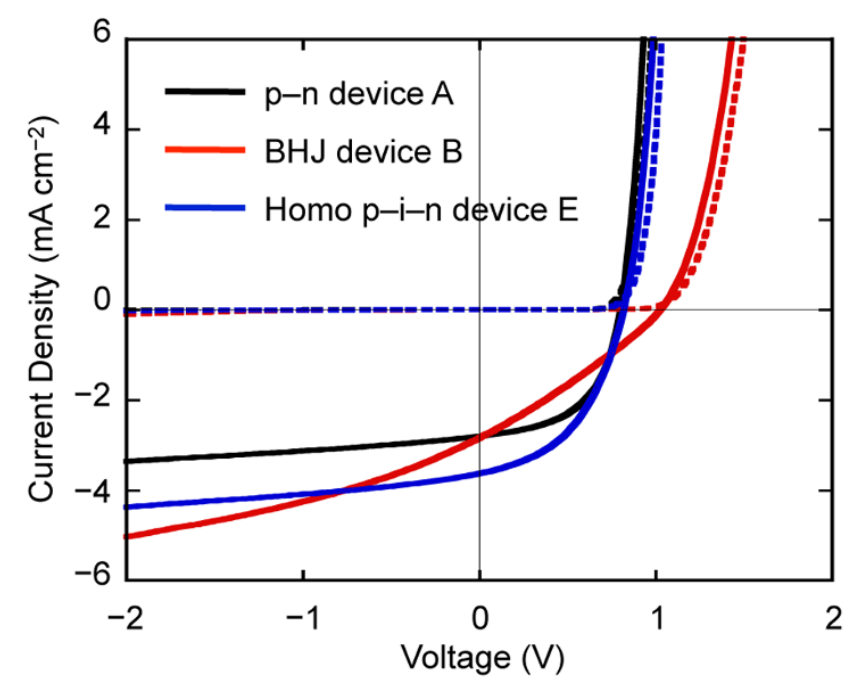

Figure $3 \mid J-V$ curves for devices A, B, and E. Solid lines: under AM1.5G illumination at $100 \mathrm{~mW} \mathrm{~cm}$, dashed lines: in the dark.

$420 \mathrm{~nm}$. This indicates that the blend film prepared by the photoprecursor approach is advantageous for charge-carrier photogeneration owing to the large D-A interface area within the film, allowing more excitons to reach the interface to dissociate as in the case of those BHJ films prepared by conventional deposition methods. Device E has the thickest active layer $(123 \mathrm{~nm})$ among the three devices; however, its IQE remains at a relatively high level to reach around $45 \%$ at maximum (Figure $4 \mathrm{c}$ ). Thus, the employment of triple-layer structure in this case did not negatively affect the photocurrent generation efficiency as compared to the BHJ system.

Table 1 includes data from other devices with greater active-layer thicknesses (devices C, D, F, and G). In the BHJ series, increasing the thickness from $67 \mathrm{~nm}$ for device B to $124 \mathrm{~nm}$ for C, and to $199 \mathrm{~nm}$ for $\mathrm{D}$ resulted in gradual decrease of both $J_{\mathrm{SC}}$ and FF (Table 1 and Supplementary Figure S12). The PCE also decreased from $0.90 \%$ for A to $0.33 \%$ for C. On the other hand, in the homo $\mathrm{p}-\mathrm{i}-\mathrm{n}$ series, increasing the thickness from $123 \mathrm{~nm}$ for device E to $153 \mathrm{~nm}$ for $\mathrm{F}$, and to $223 \mathrm{~nm}$ for $\mathrm{G}$ brought about slight increase of $J_{\mathrm{SC}}$ and decrease of FF (Table 1 and Figure 5). Thus, there is a trade-off relation between $J_{\mathrm{SC}}$ and FF. As a result, device $\mathrm{F}$ gave the best PCE of $1.50 \%$ with a $J_{\mathrm{SC}}$ of $3.78 \mathrm{~mA} \mathrm{~cm}^{-2}$, a FF of $44.7 \%$, and a $R_{\mathrm{S}}$ of $59 \Omega \mathrm{cm}^{2}$.

To clarify the relationship between film structure and device performance, surface morphologies of a pure DTA film (p-layer) and a DTA : $\mathrm{PC}_{71} \mathrm{BM}$ blend film (i-layer) were observed by atomic force microscopy (AFM) as shown in Figure $6 a$ and $b$. The pure DTA film exhibited granular features of several hundred nanometers in diameter; in contrast, the blend film exhibited a "sea-island" structure where aggregated grains ("islands") of ca. 200-250 nm were observed in the "sea" having a smooth surface. The root-mean square (RMS) values of surface roughness are $19.4 \mathrm{~nm}$ for the pure film and $14.1 \mathrm{~nm}$ for the blend film. The shapes of grains observed in the DTA : PC $_{71} \mathrm{BM}$ blend film is similar to those in the DTA neat film, suggesting that the major component of these grains is DTA. In contrast, no pronounced structure was seen in the sea part, implying that grains of DTA are eroded by mixing with $\mathrm{PC}_{71} \mathrm{BM}$, and the smooth composite based on relatively well-mixed DTA and $\mathrm{PC}_{71} \mathrm{BM}$ fills the gap between grains. (More detailed analysis of the component distribution in this "sea-island" structure will be reported elsewhere.)

The film structures were also analyzed by out-of-plane XRD measurements (Figure S10a and b). The pure DTA film showed a series of peaks assignable to the $(h 00)$ reflections (Figure $\mathrm{S} 10 \mathrm{a})$. The diffraction peak at $2 \theta=4.89^{\circ}$ corresponding to a $d$-spacing of $18.1 \AA$ was in (a)

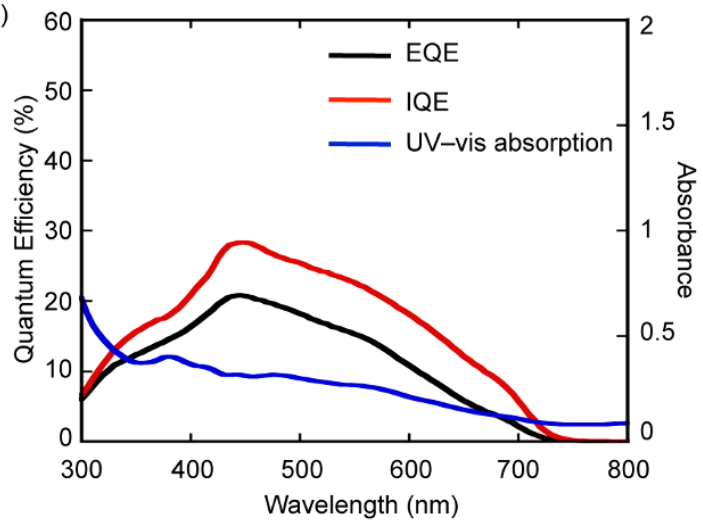

(b)

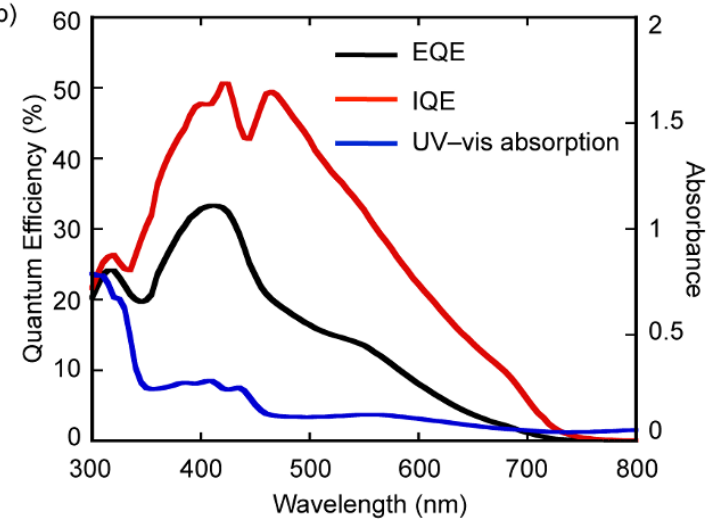

(c)

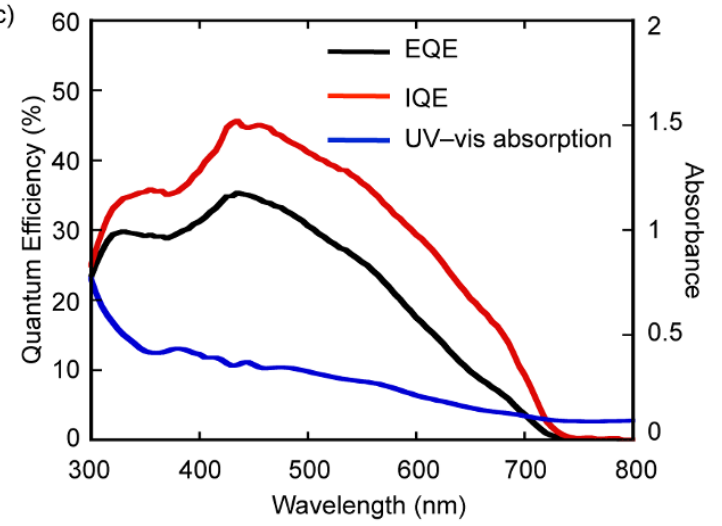

Figure $4 \mid$ EQE, IQE, and UV-vis absorption spectra for devices A (a), B (b), and $\mathrm{E}$ (c).

good agreement with the (200) reflection of the single-crystal structure $(a=34.2 \AA)^{35}$. In contrast, the DTA : $\mathrm{PC}_{71} \mathrm{BM}$ blend film did not give any peaks (Figure $\mathrm{S} 10 \mathrm{~b}$ ) suggesting its considerably attenuated crystallinity compared to the neat DTA film. Based on these results, it can be assumed that the pure DTA film (p-layer) has higher crystallinity and is more suitable for carrier extraction and transport, while the less crystalline blend film (i-layer) provides a larger $\mathrm{p}-\mathrm{n}$ junction that is advantageous for exciton harvesting.

The homo $\mathrm{p}-\mathrm{i}-\mathrm{n}$ devices showed superior photovoltaic performance to the $\mathrm{p}-\mathrm{n}$ and $\mathrm{BHJ}$ counterparts. This improvement can be attributed to the combination of the complementary strengths of the $\mathrm{p}-\mathrm{n}$ and $\mathrm{BHJ}$ devices; i.e., efficient charge carrier extraction in the $\mathrm{p}-$ $\mathrm{n}$ device and efficient charge carrier photogeneration in the $\mathrm{BHJ}$ device. Indeed, the estimated IQE of the homo $p-i-n$ device $E$ is similar to that of the $\mathrm{BHJ}$ device $\mathrm{B}$, and the $\mathrm{FF}$ is close to that of the $\mathrm{p}-\mathrm{n}$ device $\mathrm{A}$. In addition, there are two benefits assumed for the $\mathrm{p}-\mathrm{i}-\mathrm{n}$ architecture. One is the increase of $\mathrm{p}-\mathrm{n}$ junction area at the $\mathrm{p}-\mathrm{i}$ 


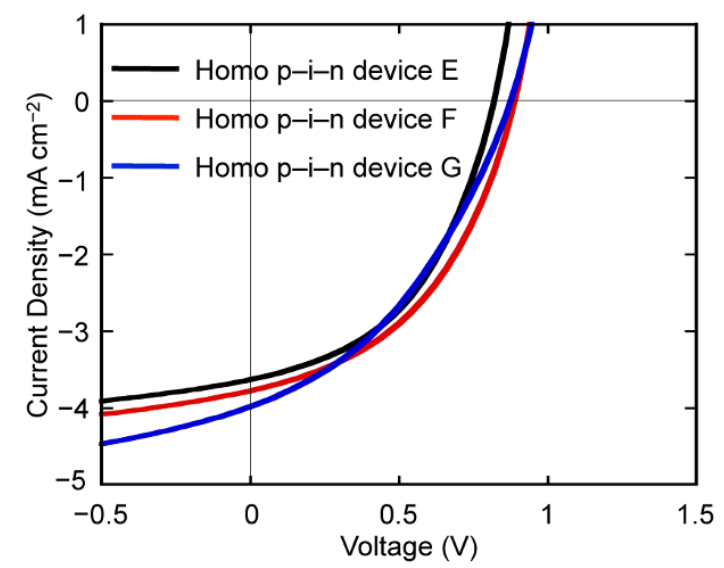

Figure $5 \mid J-V$ curves for devices E, F, and G under AM1.5G illumination at $100 \mathrm{~mW} \mathrm{~cm}^{-2}$.

and $\mathrm{i}-\mathrm{n}$ interfaces. When the lateral dimensions of domains in the $\mathrm{i}$ layer are larger than the thickness of the layer, which would be the case for device $\mathrm{E}$ considering that the active-layer thickness of device $\mathrm{B}$ is $67 \mathrm{~nm}$ and the size of grains ranges well over one hundred nanometers, these interfaces would provide a considerable addition in the $\mathrm{p}-\mathrm{n}$ junction area, thereby improving the carrier photogeneration efficiency. The other benefit is the improvement of rectification behavior as a diode in the dark. Device $\mathrm{E}$ showed a larger forward current in the dark than device B (Figure 3), indicating that the pure
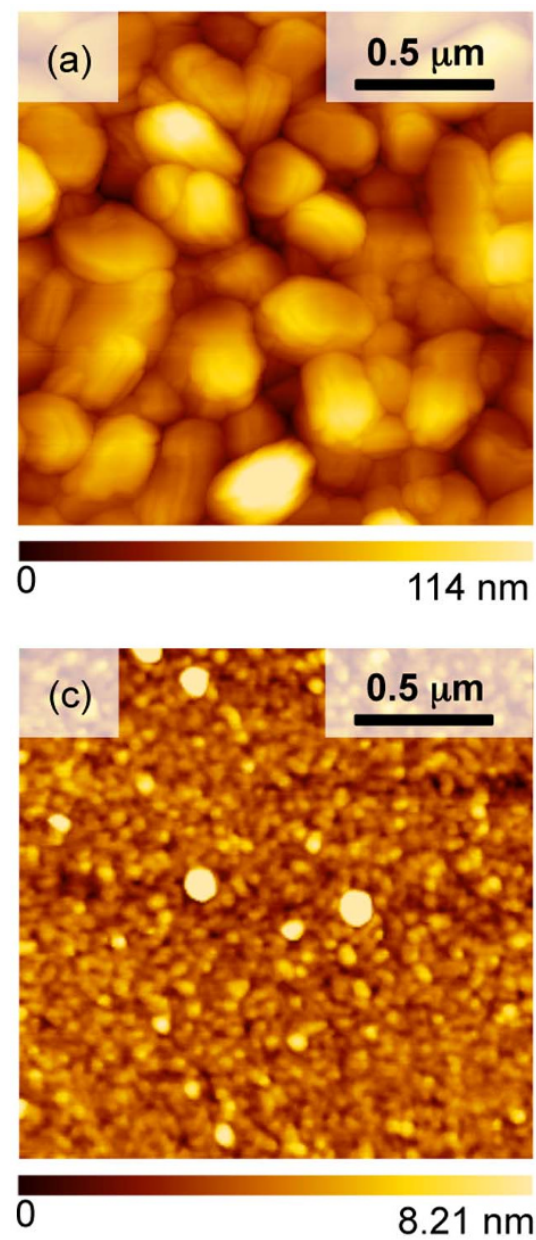

$\mathrm{p}$ - or n-film at the electrode-organic interface is more suitable for carrier injection than the blend film. These observations suggest that the high resistance of the i-layer could be redeemed by sandwiching it between the pure $\mathrm{p}$ and $\mathrm{n}$-layers, and consequently, the $\mathrm{p}-\mathrm{i}-\mathrm{n}$ devices afforded the enhanced carrier photogeneration efficiencies.

Encouraged by these results, we next explored the feasibility of employing tailor-made materials in each layer of the $\mathrm{p}-\mathrm{i}-\mathrm{n}$ structure via the photoprecursor approach. In this proof-of-concept study of solution-processed 'hetero p-i-n' devices, EH-DBTA (Figure 1b) was chosen for the i-layer and DTA was used in the p-layer as p-type materials. EH-DBTA was assumed to be a superior option to DTA for the i-layer because of two factors: (1) better photoabsorption capability owing to the more $\pi$-extended structure and (2) higher miscibility with the n-type material $\left(\mathrm{PC}_{71} \mathrm{BM}\right)$ owing to the alkyl substituents. On the other hand, DTA would serve as a better option for the p-layer because of its higher transparency.

The photovoltaic performances of the hetero $\mathrm{p}-\mathrm{i}-\mathrm{n}$ devices are summarized in Table 1 (runs 8-10) and their $J-V$ curves are plotted in Figure S14. The highest PCE of $2.89 \%$ associated with a Voc of $0.91 \mathrm{~V}$ and a FF of $55.0 \%$ was obtained when the p-, i-, and n-layers were deposited from solutions of 5,10 , and $5 \mathrm{mg} \mathrm{ml}^{-1}$, respectively (device I). The PCE is nearly twice as high as that of the best homo p$\mathrm{i}-\mathrm{n}$ device (device $\mathrm{F}, \mathrm{PCE}=1.50 \%$ ). Figure $7 \mathrm{a}$ compares the $J-V$ curves of devices F and I, clearly showing that the improvement in $J_{\mathrm{SC}}$ (from 3.78 to $5.78 \mathrm{~mA} \mathrm{~cm}^{-2}$ ) mostly accounts for the enhanced PCE.

The UV-vis absorption, EQE, and IQE spectra of the hetero $\mathrm{p}-\mathrm{i}-\mathrm{n}$ device I are plotted in Figure 7c. Compared to the homo p-i-n device $\mathrm{E}$ (Figure 4c), the EQE of this hetero device is considerably increased
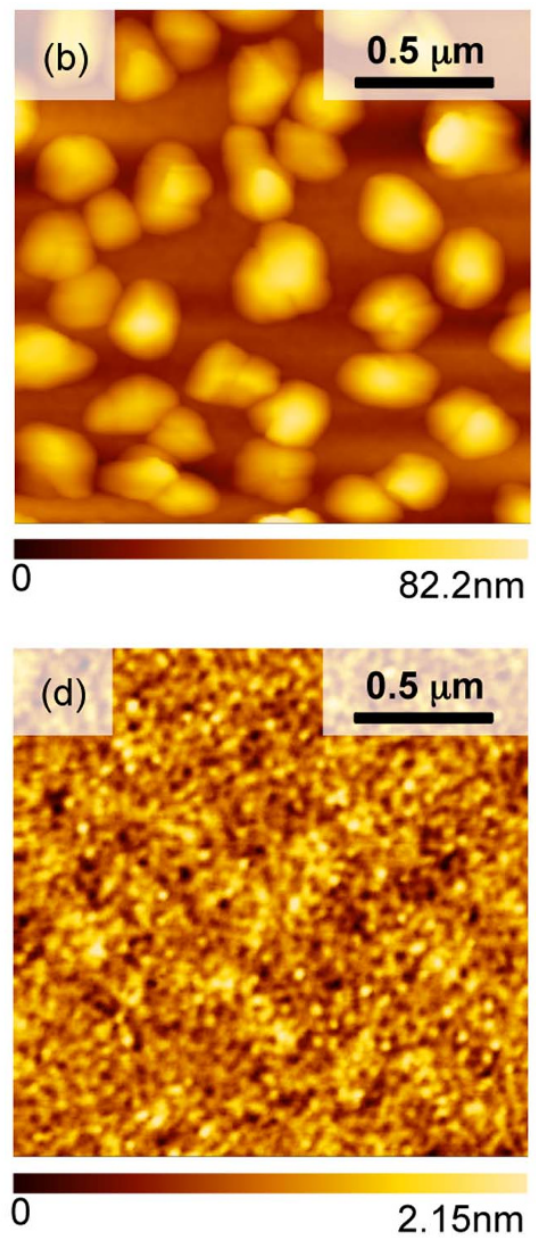

Figure 6 Tapping-mode AFM images of a pure DTA film (a), DTA : PC $_{71}$ BM (2:1) blend film (b), pure EH-DBTA film (c), and EH-DBTA : PC ${ }_{71}$ BM $^{-}$ $(2: 1)$ blend film (d). 
in the 350-550 $\mathrm{nm}$ range corresponding very well to the absorption peaks of the EH-DBTA film, which are much stronger than those of the DTA film (Figure 7b). However, the enhancement in absorptivity does not fully explain the improved photocurrent sensitivity. Comparison of IQE curves of the homo and hetero devices indicates that the conversion of absorbed light to current is more efficient in the hetero device independent of the wavelength. Specifically, the maximum IQE reaches $76 \%$ around $470 \mathrm{~nm}$ for the hetero $\mathrm{p}-\mathrm{i}-\mathrm{n}$ device, while it is only $46 \%$ around $435 \mathrm{~nm}$ for the homo $\mathrm{p}-\mathrm{i}-\mathrm{n}$ device; in addition, the IQE in the longer wavelength region (500$700 \mathrm{~nm}$ ) is higher for the hetero device, although the sensitivity in this region thoroughly depends on $\mathrm{PC}_{71} \mathrm{BM}$.

With these in consideration, it was presumed that an appreciable portion of the improvement in Jsc might be due to the change in film morphology. AFM observation of an EH-DBTA : PC $_{71}$ BM blend film indeed showed a much smoother surface and a more finely mixed morphology (Figure 6d) as compared to the DTA: $\mathrm{PC}_{71} \mathrm{BM}$ film (Figure 6b). This seems reflecting the lower tendency of $\mathrm{EH}$ DBTA, in comparison with DTA, to form large self-aggregates (Figures $6 \mathrm{a}$ and $6 \mathrm{c}$ ). The morphology of the EH-DBTA: $\mathrm{PC}_{71} \mathrm{BM}$ blend film should have led to a considerable increase in donoracceptor heterojunction area within the i-layer, thereby enhancing carrier generation in comparison with the case of DTA: $\mathrm{PC}_{71} \mathrm{BM}$. Here, it would be worth noting that the corresponding $\mathrm{BHJ}$ device based on EH-DBTA gave the maximum PCE of only $0.85 \%$ (Jsc = $3.71 \mathrm{~mA} \mathrm{~cm}^{-2}, V \mathrm{Oc}=0.78 \mathrm{~V}, \mathrm{FF}=29.4 \%$, and $R \mathrm{~s}=169 \Omega \mathrm{cm}^{2}$ ) (Supplementary Table S4 and Figure S13), which is not improved from the best $\mathrm{BHJ}$ device based on DTA (PCE $=0.90 \%$, Table 1 , run 2 ). These results strongly support the effectiveness of the $p-i-n$ structure in improving PCE by redeeming the high resistance of $\mathrm{BHJ}$ films and increasing carrier transport efficiency.

Finally, the superiority of hetero $\mathrm{p}-\mathrm{i}-\mathrm{n}$ devices to corresponding homo $\mathrm{p}-\mathrm{i}-\mathrm{n}$ devices was further confirmed by examining homo $\mathrm{p}-\mathrm{i}-$ n devices based on EH-DBTA (Supplementary Table S6 and Figure S15). In this case again, the hetero device showed higher performance (the best PCEs are $2.89 \%$ for the hetero device and $2.46 \%$ for the homo device) associated with generally higher EQE values regardless of the wavelength. Thus, it was experimentally confirmed that not only the higher transparency of DTA, but also other factors such as higher hole-transport capability contributed to the enhanced photovoltaic performance of the hetero $\mathrm{p}-\mathrm{i}-\mathrm{n}$ device.

\section{Conclusions}

Organic active layers of the $\mathrm{p}-\mathrm{i}-\mathrm{n}$ structure were solution-processed via the photoprecursor approach employing $\alpha$-diketone-type precursors of anthracene derivatives. The photovoltaic performance of homo $\mathrm{p}-\mathrm{i}-\mathrm{n}$ devices based on DTA was more than $20 \%$ higher as compared to the corresponding $\mathrm{p}-\mathrm{n}$ and $\mathrm{BHJ}$ systems. The systematic comparison of different types of devices indicated that the neat $p$ and n-layers enhanced charge extraction and carrier injection, and the blend i-layer improved charge photogeneration. We also examined the prototype hetero $\mathrm{p}-\mathrm{i}-\mathrm{n}$ system in which EH-DBTA was used for the i-layer and DTA for the p-layer. The resulting devices afforded significantly enhanced photovoltaic performance compared to the homo $\mathrm{p}-\mathrm{i}-\mathrm{n}$ devices. With these very simple $\mathrm{p}$-type materials, the efficiency of hetero $\mathrm{p}-\mathrm{i}-\mathrm{n}$ device is already comparable to those obtained with more exotic molecular materials ${ }^{36,37}$ or benchmark polymers such as poly(3-hexylthiophene $)^{38,39}$. The enhancement in PCE was attributed to the better miscibility with $\mathrm{PC}_{71} \mathrm{BM}$ and higher photoabsorption capability inherent in EH-DBTA as compared to DTA. In the BHJ system, on the other hand, the replacement of DTA with EH-DBTA did not lead to any enhancement in photovoltaic performance even with those favorable properties of EH-DBTA. This would serve as a manifestation of the complexity accompanied with optimization of the BHJ system and, at the same time, as additional support for the advantage of employing the $\mathrm{p}-\mathrm{i}-\mathrm{n}$ structure.
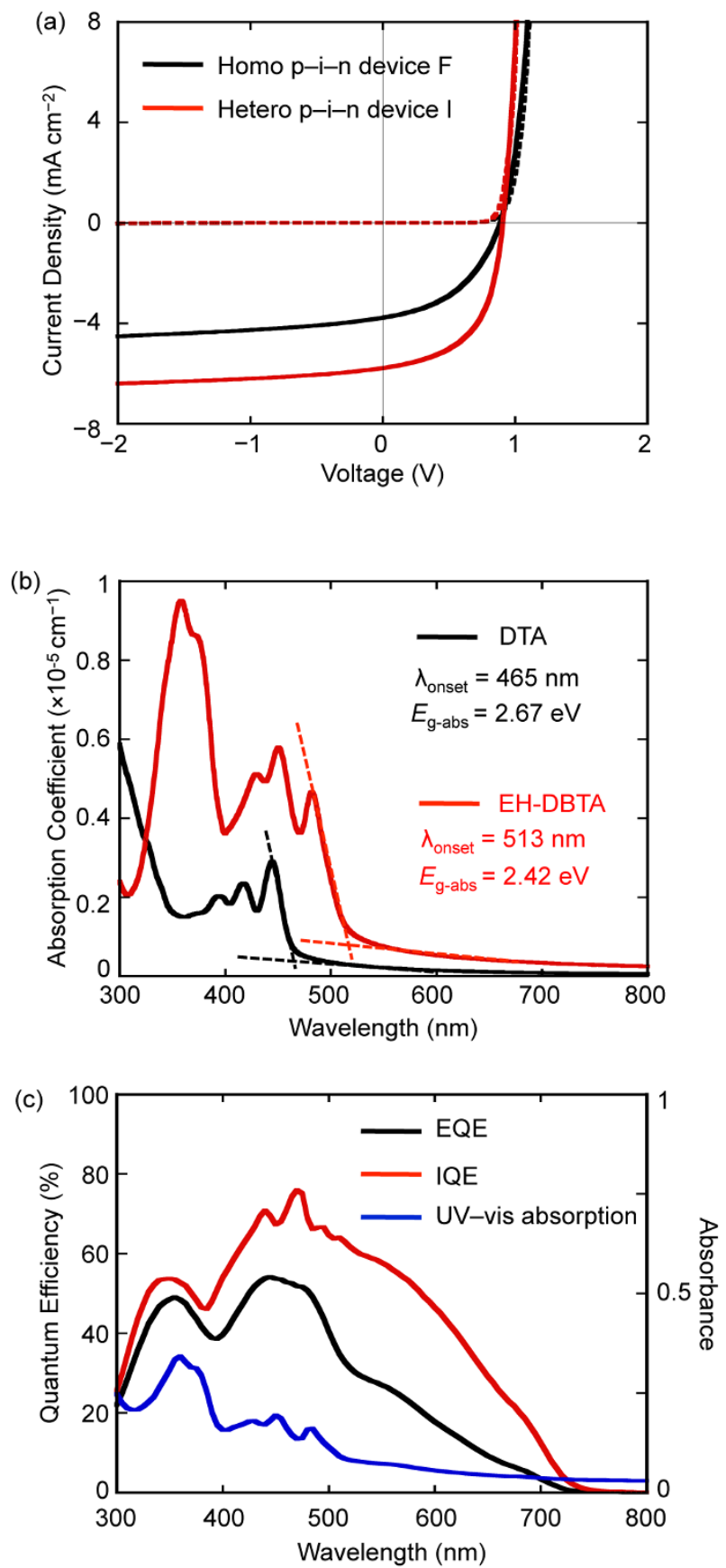

Figure $7 \mid$ (a) Comparison of $J-V$ curves of devices F and I; solid lines: under AM1.5G illumination at $100 \mathrm{~mW} \mathrm{~cm}^{-2}$, dashed lines: in the dark. (b) Absorption spectra of DTA and EH-DBTA in the thin-film form: the lowest transition energies ( $E_{\mathrm{g}}$-abs) were determined at the intersection of the line tangent to the long wavelength side of the band and the corrected baseline. The thin films were prepared by spin-coating chloroform solutions ( $5 \mathrm{mg} \mathrm{ml}^{-1}, 800 \mathrm{rpm}, 30 \mathrm{~s}$ ) of each compound atop glass substrates followed by photoirradiation $\left(470 \mathrm{~nm} \mathrm{LED}, 550 \mathrm{~mW} \mathrm{~cm} \mathrm{~cm}^{-2}\right.$, $30 \mathrm{~min}$ ). (c) The EQE, IQE, and UV-vis absorption spectra for device I.

All these results clearly demonstrate the effectiveness of the photoprecursor approach as a means for controlled preparation of multi-component organic active layers via solution techniques. This proof-of-concept study may open a new way to highly efficient, cost-effective solution-processed OPVs and related organic electronic devices. Towards this goal, future work will involve careful optimization of photoprecursor materials for each applications and 
examination of compatibility of the photoprecursor approach with low-cost patterning or printing technologies.

\section{Methods}

Materials. DTADK was synthesized according to the reported procedure ${ }^{26}$. The new photoprecursor EH-DBTDK was synthesized as outlined in Figure S1 in Supporting Information, and characterized by nuclear magnetic resonance spectroscopy (NMR), infrared resonance spectroscopy (IR), and mass spectroscopy. The purities of these compounds were confirmed to be $>99 \%$ by high performance liquid chromatography (HPLC). $\mathrm{PC}_{71} \mathrm{BM}$ was purchased from Luminescence Technology Corp. and used as received. Other reagents and solvents were reagent grade purchased from commercial vendors and used without further purification if not specified otherwise in Supporting Information.

Device fabrication and evaluation. Indium-tin-oxide (ITO)-patterned glass substrates $(20 \times 25 \mathrm{~mm}, 15 \mathrm{ohm}$ per square) were cleaned by gentle rubbing with an acetone-soaked wipe for ca. $5 \mathrm{~s}$, sonication in acetone and isopropanol for $10 \mathrm{~min}$ each, and exposure to boiling isopropanol for $10 \mathrm{~min}$. The washed substrates were further treated in a UV-O ${ }_{3}$ cleaner (Filgen, UV253V8) for $20 \mathrm{~min}$, and the poly $(3,4$ ethylenedioxythiophene) : poly(4-styrenesulfonate) layer (PEDOT : PSS, Clevios P VP AI4083) was spin coated at $5000 \mathrm{rpm}$ for $40 \mathrm{~s}$ in air followed by a thermal annealing treatment at $120^{\circ} \mathrm{C}$ for $20 \mathrm{~min}$ in air. The thickness of the resulting PEDOT : PSS layer was about $30 \mathrm{~nm}$. The substrates were then transferred to a $\mathrm{N}_{2}$ filled glove box $\left(<0.5 \mathrm{ppm} \mathrm{O}_{2}\right.$ and $\left.\mathrm{H}_{2} \mathrm{O}\right)$ for preparation of the organic layers. Finally, calcium $(10 \mathrm{~nm})$ and aluminum $(80 \mathrm{~nm})$ were vapor deposited at high vacuum $\left(\sim 10^{-5} \mathrm{~Pa}\right)$ through a shadow mask that defined an active area of $4.0 \mathrm{~mm}^{2}$.

Current-voltage $(J-V)$ curves were measured using a Keithley 2400 source measurement unit under AM1.5G illumination at an intensity of $100 \mathrm{~mW} \mathrm{~cm}$.- using a solar simulator (Bunko-keiki, CEP-2000TF). The external quantum efficiency (EQE) spectra were obtained under illumination of monochromatic light using the same system. The UV-vis absorption spectra of the organic films including the PEDOT : PSS layer were recorded using a JASCO V-650 spectrophotometer by the transmittance mode. The internal quantum efficiency (IQE) values were roughly estimated from the EQE and UV-vis absorption spectra according to the previously employed method by $\mathrm{Yu}$ et $\mathrm{al}^{40}$. Although deviations from the "true" values are expected, the estimated IQEs would still provide useful information in systematic comparison between devices.

Film characterization. The surface morphology of organic films was observed by an SII SPA400/SPI3800N atomic force microscope (AFM) in tapping mode using a silicon probe with a resonant frequency of $138 \mathrm{kHz}$ and a force constant of $16 \mathrm{~N} \mathrm{~m}^{-1}$ (SII, SI-DF20). The bulk structure of thin-films was evaluated by out-of-plane X-ray diffraction (XRD) measurements using a Rigaku SmartLab diffractometer equipped with a rotating anode $(\mathrm{Cu} K \alpha$ radiation, $\lambda=1.5418 \AA)$. The thin-film samples were prepared on glass substrates through the photoprecursor approach. The pure DTA film was prepared by spin-coating of a chloroform solution $\left(5 \mathrm{mg} \mathrm{ml}^{-1}, 800 \mathrm{rpm}\right.$, $30 \mathrm{~s}$ ) of DTADK followed by photoirradiation ( $470 \mathrm{~nm}$ LED, $550 \mathrm{~mW} \mathrm{~cm}{ }^{-2}$, $30 \mathrm{~min})$. The DTA: $\mathrm{PC}_{71} \mathrm{BM}$ blend film was prepared by spin-coating of a chloroform solution $\left(10 \mathrm{mg} \mathrm{ml}^{-1}, 800 \mathrm{rpm}, 30 \mathrm{~s}\right)$ of DTADK: $\mathrm{PC}_{71} \mathrm{BM}$ followed by photoirradiation (470 $\mathrm{nm} \mathrm{LED,} 550 \mathrm{~mW} \mathrm{~cm}{ }^{-2}, 30 \mathrm{~min}$ ).

1. Campoy-Quiles, M. et al. Morphology evolution via self-organization and lateral and vertical diffusion in polymer: fullerene solar cell blends. Nat. Mater. 7, 158-164 (2008).

2. Nam, Y. M., Huh, J. \& Jo, W. H. Effect of the vertical composition gradient of active layer on the performance of bulk-heterojunction organic photovoltaic cell. J. Appl. Phys. 110, 114521 (2011).

3. Xiao, Z. et al. Universal formation of compositionally graded bulk heterojunction for efficiency enhancement in organic photovoltaics. Adv. Mater. 26, 3068-3075 (2014)

4. Gevaerts, V. S., Koster, L. J. A., Wienk, M. M. \& Janssen, R. A. J. Discriminating between Bilayer and Bulk Heterojunction Polymer: Fullerene Solar Cells Using the External Quantum Efficiency. ACS Appl. Mater. Interfaces 3, 3252-3255 (2011).

5. Cheng, P., Hou, J. H., Li, Y. F. \& Zhan, X. W. Layer-by-Layer Solution-Processed Low-Bandgap Polymer-PC ${ }_{61}$ BM Solar Cells with High Efficiency. Adv. Energy Mater. 4, 1301349 (2014).

6. Lin, Y. Z. et al. Small-Molecule Solar Cells with Fill Factors up to 0.75 via a Layerby-Layer Solution Process. Adv. Energy Mater. 4, 1300626 (2014).

7. Lee, K. H. et al. Morphology of All-Solution-Processed "Bilayer" Organic Solar Cells. Adv. Mater. 23, 766-770 (2011).

8. Kim, D. H. et al. Sequentially solution-processed, nanostructured polymer photovoltaics using selective solvents. Enrgy Environ. Sci. 7, 1103-1109 (2014).

9. Chen, D., Liu, F., Wang, C., Nakahara, A. \& Russell, T. P. Bulk Heterojunction Photovoltaic Active Layers via Bilayer Interdiffusion. Nano Lett. 11, 2071-2078 (2011).

10. Lee, D. H., Michael Yang, Y., You, J., Richard, E. \& Li, G. Immiscible solvents enabled nanostructure formation for efficient polymer photovoltaic cells. Nanotechnology 25, 295401 (2014).
11. Xiao, Y. et al. Enhanced efficiency of organic solar cells by mixed orthogonal solvents. Org. Electron. 15, 2007-2013 (2014).

12. Tao, C. et al. Controlling Hierarchy in Solution-processed Polymer Solar Cells Based on Crosslinked P3HT. Adv. Energy Mater. 3, 105-112 (2013).

13. Png, R. Q. et al. High-performance polymer semiconducting heterostructure devices by nitrene-mediated photocrosslinking of alkyl side chains. Nat. Mater. $\mathbf{9}$, 152-158 (2010).

14. Suzuki, M. et al. Synthesis and photoreactivity of $\alpha$-diketone-type precursors of acenes and their use in organic-device fabrication. J. Photochem. Photobiol. C. 18, 50-70 (2014).

15. Yamada, H. et al. FET performance and substitution effect on 2,6dithienylanthracene devices prepared by photoirradiation of their diketone precursors. Chem. Commun. 48, 11136-11138 (2012).

16. Nakayama, K., Ohashi, C., Oikawa, Y., Motoyama, T. \& Yamada, H. Characterization and field-effect transistor performance of printed pentacene films prepared by photoconversion of a soluble precursor. J. Mate. Chem. C 1, 6244-6251 (2013).

17. Yamada, H. et al. Solution-processed anthradithiophene-PCBM p-n junction photovoltaic cells fabricated by using the photoprecursor method. Chem. Commun. 49, 11638-11640 (2013).

18. Zuniga, C. A., Barlow, S. \& Marder, S. R. Approaches to Solution-Processed Multilayer Organic Light-Emitting Diodes Based on Cross-Linking. Chem. Mat. 23, 658-681 (2011).

19. Jin, Z. W. \& Wang, J. Z. PIN architecture for ultrasensitive organic thin film photoconductors. Sci. Rep. 4, 05331 (2014).

20. Hiramoto, M., Fujiwara, H. \& Yokoyama, M. Three-layered organic solar cell with a photoactive interlayer of codeposited pigments. Appl. Phys. Lett. 58, 1062-1064 (1991).

21. Hiramoto, M., Fujiwara, H. \& Yokoyama, M. P-I-N Like Behavior in 3-Layered Organic Solar-Cells Having a Co-Deposited Interlayer of Pigments. J. Appl. Phys. 72, 3781-3787 (1992)

22. Wang, Z. Q. et al. Highly efficient organic p-i-n photovoltaic cells based on tetraphenyldibenzoperiflanthene and fullerene $\mathrm{C}_{70}$. Energy Environ. Sci. 6, 249-255 (2013).

23. Maennig, B. et al. Organic p-i-n solar cells. Appl. Phys. A-Mater. Sci. Process. 79, 1-14 (2004).

24. Walzer, K., Maennig, B., Pfeiffer, M. \& Leo, K. Highly efficient organic devices based on electrically doped transport layers. Chem. Rev. 107, 1233-1271 (2007).

25. Matsuo, Y. et al. Columnar Structure in Bulk Heterojunction in SolutionProcessable Three-Layered p-i-n Organic Photovoltaic Devices Using Tetrabenzoporphyrin Precursor and Silylmethyl[60]fullerene. J. Am. Chem. Soc. 131, 16048-16050 (2009).

26. Yamada, H. et al. Effective photochemical synthesis of an air-stable anthracenebased organic semiconductor from its diketone precursor. Tetrahedron Lett. 47, 7501-7504 (2006).

27. Motoyama, T. et al. Bulk-Heterojunction Organic Photovoltaic Devices Fabricated Using Asymmetric Soluble Anthracene Core Photoprecursors. Jpn. J. Appl. Phys. 53, 01AB02 (2014)

28. Shin, W., Yasuda, T., Watanabe, G., Yang, Y. S. \& Adachi, C. Self-Organizing Mesomorphic Diketopyrrolopyrrole Derivatives for Efficient Solution-Processed Organic Solar Cells. Chem. Mat. 25, 2549-2556 (2013).

29. Zhu, Y. X., Xu, X. F., Zhang, L. J., Chen, J. W. \& Cao, Y. High efficiency inverted polymeric bulk-heterojunction solar cells with hydrophilic conjugated polymers as cathode interlayer on ITO. Sol. Energy Mater. Sol. Cells 97, 83-88 (2012).

30. Veldman, D., Meskers, S. C. J. \& Janssen, R. A. J. The Energy of Charge-Transfer States in Electron Donor-Acceptor Blends: Insight into the Energy Losses in Organic Solar Cells. Adv. Funct. Mater. 19, 1939-1948 (2009).

31. Schlenker, C. W. \& Thompson, M. E. The molecular nature of photovoltage losses in organic solar cells. Chem. Commun. 47, 3702-3716 (2011).

32. Vandewal, K., Tvingstedt, K., Gadisa, A., Inganas, O. \& Manca, J. V. On the origin of the open-circuit voltage of polymer-fullerene solar cells. Nat. Mater. 8, 904-909 (2009).

33. Li, W. W. et al. Tailoring side chains of low band gap polymers for high efficiency polymer solar cells. Polymer 51, 3031-3038 (2010).

34. Hedley, G. J. et al. Determining the optimum morphology in high-performance polymer-fullerene organic photovoltaic cells. Nat. Commun. 4, 2867 (2013).

35. Meng, H. et al. High-performance, stable organic thin-film field-effect transistors based on bis-5'-alkylthiophen-2'-yl-2,6-anthracene semiconductors. J. Am. Chem. Soc. 127, 2406-2407 (2005).

36. Chen, Y. S., Wan, X. J. \& Long, G. K. High Performance Photovoltaic Applications Using Solution-Processed Small Molecules. Acc. Chem. Res. 46, 2645-2655 (2013).

37. Mishra, A. \& Bauerle, P. Small Molecule Organic Semiconductors on the Move: Promises for Future Solar Energy Technology. Angew. Chem.-Int. Edit. 51, 2020-2067 (2012).

38. An, Q. S. et al. Improved Efficiency of Bulk Heterojunction Polymer Solar Cells by Doping Low-Bandgap Small Molecules. ACS Appl. Mater. Interfaces 6, 6537-6544 (2014).

39. Wang, D. H., Kim, J. K., Seo, J. H., Park, O. O. \& Park, J. H. Stability comparison: A $\mathrm{PCDTBT} / \mathrm{PC}_{71} \mathrm{BM}$ bulk-heterojunction versus a $\mathrm{P} 3 \mathrm{HT} / \mathrm{PC}_{71} \mathrm{BM}$ bulkheterojunction. Sol. Energy Mater. Sol. Cells 101, 249-255 (2012). 
40. Liang, Y. Y. et al. For the Bright Future-Bulk Heterojunction Polymer Solar Cells with Power Conversion Efficiency of 7.4\%. Adv. Mater. 22, E135-E138 (2010).

\section{Acknowledgments}

This research was supported by the CREST program of the Japan Science and Technology Agency (JST), a Grant-in-Aid for Scientific Research (25288092 for HY) from the Japan Society for the Promotion of Science (JSPS), Japan Regional Innovation Strategy Program by the Excellence (J-RISE) sponsored by JST, the Green Photonics Project in NAIST sponsored by the Ministry of Education, Culture, Sports, Science and Technology (MEXT), Japan, and the program for promoting the enhancement of research universities in NAIST supported by MEXT. We thank Ms. Yoshiko Nishikawa and Ms. Naoko Kishimoto at NAIST for the help in spectroscopic measurements for material characterization.

\section{Author contributions}

Y.Y. and M.S. contributed equally to this work and wrote the manuscript. Y.Y., M.S., H.Y. and K.N. developed the ideas. M.S., S.S. and S.I. performed material synthesis and

characterization. Y.Y., T.M., C.K. and K.T. carried out the fabrication and characterization of OPV devices. Y.Y. and M.S. contributed to film fabrications, AFM measurements, and XRD measurements. All authors agree the contents of the paper.

\section{Additional information}

Supplementary information accompanies this paper at http://www.nature.com/ scientificreports

Competing financial interests: The authors declare no competing financial interests.

How to cite this article: Yamaguchi, Y. et al. Photoprecursor approach as an effective means for preparing multilayer organic semiconducting thin films by solution processes. Sci. Rep. 4, 7151; DOI:10.1038/srep07151 (2014)

This work is licensed under a Creative Commons Attribution-NonCommercialNoDerivs 4.0 International License. The images or other third party material in this article are included in the article's Creative Commons license, unless indicated otherwise in the credit line; if the material is not included under the Creative Commons license, users will need to obtain permission from the license holder in order to reproduce the material. To view a copy of this license, visit http:// creativecommons.org/licenses/by-nc-nd/4.0/ 